\title{
Probiotic and synbiotic safety in infants under two years of age
}

\author{
M. van den Nieuwboer ${ }^{1,2}$, E. Claassen ${ }^{1,3}$, L. Morelli ${ }^{4}$, F. Guarner ${ }^{5}$ and R.J. Brummer ${ }^{6}$ \\ ${ }^{1}$ VU University Amsterdam, Athena Institute, De Boelelaan 1085, 1081 HV Amsterdam, the Netherlands; ${ }^{2}$ University of \\ Amsterdam, Swammerdam Institute for Life Sciences, Kruislaan 318, 1098 SM Amsterdam, the Netherlands; ${ }^{3}$ Erasmus \\ Medical Center, Department of Viroscience, P.O. Box 2040, 3000 CA Rotterdam, the Netherlands; ${ }^{4}$ Food Microbiology and \\ Biotechnology, Istituto di Microbiologia Università Cattolica S.C., Via Emilia Parmense 84, 29122 Piacenza, Italy, ${ }^{5}$ Digestive \\ System Research Unit, CIBERehd, University Hospital Vall d'Hebron, 08035 Barcelona, Spain, ${ }^{6}$ School of Health and Medical \\ Sciences, Faculty of Medicine and Health, Örebro University, 70182 Örebro, Sweden; prof.eric.claassen@gmail.com
}

Received: 23 August 2013 / Accepted: 15 October 2013

(c) 2014 Wageningen Academic Publishers

\section{RESEARCH ARTICLE}

\begin{abstract}
In this study, we systematically evaluated safety aspects in clinical trials with probiotics and synbiotics in young infants (0-2 years of age). This study is an update of earlier reports and covers the recent literature from 2008-2013. The safety evaluation is performed along the Common Terminology Clinical Adverse Events (CTCAE) version 4.0 scale, hereby also providing guidance for future studies. Safety aspects are represented and related to number of participants per probiotic strain/culture, study duration, dosage, clinical condition and selected afflictions. The results show a deficiency in the precise reporting and classification of adverse events in most studies. Analysis of 57 clinical trials with probiotics and synbiotics in combination with eight follow-up studies indicate that probiotic administration to infants between 0 and 24 months is safe with regard to the evaluated strains in infants with a particular health status or susceptibility. Most adverse events and serious adverse events were considered unrelated to the study product, and there were no major safety concerns. Almost all studies concluded that none of the adverse effects were related to the study product; the study products are generally well tolerated. Finally, inconsistent, imprecise and potentially incomplete reporting as well as the variation in probiotic strains, dosages, administration regimes, study populations and reported outcomes, greatly limit the generalizability of conclusions and argue convincingly for obligatory and standardised behaviour on adverse events (CTCAE) reporting in 'food' studies.
\end{abstract}

Keywords: prebiotics, probiotics, health benefits, food safety legislation, children

\section{Introduction}

An aberrant composition of the intestinal microbiota, or dysbiosis, is associated with a variety of intestinal and other disorders, such as infections and allergies, in humans (Alonso and Guarner, 2013). In the beginning of the 1900s, it was suggested for the first time to administrate 'healthy' bacteria to restore the microbial composition and thereby inducing a therapeutic effect (Metchnikoff, 1907). One approach to modulate the intestinal flora is the use of probiotics or prebiotics. Probiotics are live microorganisms that, when administered in adequate amounts, confer a health benefit on the host (FAO, 2001; Sanders, 2008). Prebiotics are non-viable food components that modulate the microbiota and thereby confer a health benefit on the host (Pineiro et al., 2008). When probiotics are administered in combination with prebiotics, it is referred to as a synbiotic (De Vrese and Schrezenmeir, 2008). There is still some controversy regarding the efficacy of pro- and synbiotics, as studies report inconsistent results. This might be attributable to different study populations (and power of the study) and conditions, probiotic strains, dosage and study duration (Sanders et al., 2013).

However, an ever expanding number of suitably powered, randomised controlled trials (RCT) with probiotic supplementation demonstrate encouraging results for particular conditions in infants. For instance, a doubleblind RCT by Saavedra et al. (1994) demonstrated that administration of Streptococcus thermophilus and 
Bifidobacterium bifidum in infants aging from 5 to 24 months reduced the incidence of acute diarrhoea and rotavirus shedding. Additionally, meta-analyses indicate that probiotic supplementation results in a reduction in diarrhoeal duration as well as a reduced incidence of Clostridium difficile induced diarrhoea (Goldenberg et al., 2013; Sanders et al., 2013). Probiotic interventions have also clearly demonstrated to significantly reduce the incidence of necrotising enterocolitis (NEC) in very-low-birth-weight $(<1,500 \mathrm{~g})$ preterm infants (Ganguli and Walker, 2011; Lin et al., 2013). Besides the beneficial effects of probiotics on gastrointestinal disorders, clinical data also indicate a potential in other disorders, such as the prevention of atopic dermatitis by Lactobacillus rhamnosus GG supplementation (Kalliomäki et al., 2001).

The intestinal microbiota supports the human body in various physiologic and metabolic functions, such as energy storage, fermentation, synthesising amino acids and vitamins (Vyas and Ragnanathan, 2012). Equally important is the major role of the intestinal microbiota in the development, maturation and maintenance of a 'normal' immune system (Kamada et al., 2013). Studies using germfree mice demonstrate a poorly developed immune system and an altered intestinal morphology (Ping and LanJuan, 2012). Gut bacteria are able to produce short-chain fatty acids, such as acetate, propionate, and butyrate, which acidify the intestinal lumen, thereby inhibiting pathogenic growth (Alonso and Guarner, 2013). In humans, the gut microbiota colonises the mucosal surface, thereby competing with potential pathogens for nutrition and binding sites (Kamada et al., 2013). Additionally, some commensal bacteria are able to produce antimicrobial and antifungal peptides, preventing pathogens from getting a foothold in the intestines (Hardy et al., 2013). Intestinal colonisation is also associated with a higher secretory immunoglobulin A concentration, which prevents microbes from penetrating the epithelium. Finally, the gut microbiota stimulates innate and adaptive immune response. Dendritic cells and Toll-like receptors are in close contact with the intestinal microbiota, probing in the lumen, and thereby shape the natural killer (NK)-cell, T-cell and B-cell response (Hardy et al., 2013).

The foetal intestine is sterile in the womb and microbial colonisation is initiated due to extensive contact in the birth canal during labour. The intestinal microbiota further matures by close contact with the environment and breast milk (Clemente et al., 2012). Neonates that fail to acquire the normal intestinal ecosystem are at risk of developing diseases, also later in life. Studies demonstrated that preterms, predominantly colonised by bacteria in the intensive care unit, tend to have a higher risk to develop an allergy and inflammatory bowel syndrome (Hickey et $a l, 2012)$. Formula-fed infants have a more heterogeneous microbial composition, which is associated with a higher incidence of infections and more Clostridia species in the intestine compared to breast-milk fed infants (Hascoët et al., 2011).

There are several concerns regarding the potential risk associated with probiotic use, especially in an immature or compromised gut. The bacteria may translocate through the gastrointestinal barrier, thereby causing invasive infections leading to bacteraemia or sepsis. Another concern is the possibility that the metabolic activity of the microbial products might be toxic to the host. Additionally, probiotics could even have an adverse immunologic effect (Hibberd and Davidson, 2008). Although probiotics have a good safety record in humans and are designated as GRAS (generally recognised as safe) by the FAO/WHO (Von Wright, 2005), when administered to preterm infants and neonates, profound analyses and safety aspects should be taken into account before considering a probiotic therapy. There is a consensus that immune-compromised and immune-deficient individuals are more susceptible to opportunistic bacteria due to defective microbial clearance. At birth, infants do not have a fully developed immune system yet and, hence, could be at risk of fungemia and bacteraemia after probiotic administration (Boyle et al., 2006; Maródi, 2006). Indeed, bacteraemia was reported in 3 infants with short-bowel syndrome after ingestion of L. rhamnosus GG (De Groote et al., 2005; Kunz et al., 2004). Due to insufficient understanding of the probiotic properties and the interaction in the gut, safety predictions remain inaccurate. Currently, it is difficult to conclude that probiotics are 'safe' in infants, as each individual strain has to be evaluated for safety at high dosage and chronic use.

In the aftermath of safety issues in pancreatitis, we suggested that results with probiotics could never be generalised (Maassen and Claassen, 2008) and an extensive (1994-2009) exploratory safety analysis of probiotics indicated there is no increased health risk (Claassen et al., 2010; Hempel et al., 2011). However, at that time the authors indicated that, due to poorly documented interventions and a lack of adverse event (AE) reporting, probiotic safety remains uncertain. This report aims to review the safety data of probiotic and synbiotic interventions focusing on the infant population ageing 0 to 24 months old. Specifically, it will provide an update (2008-2013) with the most recent intervention studies on the previous safety analysis by Hempel et al. (2011). This analysis will provide a clear overview of any safety concerns for high-dosage and chronic probiotic use in at-risk infant populations, by taking health conditions, probiotic intake and study duration into account.

\section{Methodology}

In order to analyse the safety of probiotics and synbiotics in infants, a comprehensive literature study was conducted. The online database PubMed (National Library of Medicine, 
includes MEDLINE) was used as a source for the clinical studies. Eligible articles were retrieved using the search terms 'probiotics', 'synbiotics', 'infants' and 'clinical trials'. This search strategy was complemented with filters to solely include human studies published within the last five years (2008-2013). Thereby, all animal and in vitro studies were excluded. A full literature search was performed to ensure that all the relevant studies were included. All studies were subsequently reviewed for clinical phase and status using the clinical trials registry databases 'clinicaltrials. gov' and 'isrctn.org.' The articles were considered eligible if the researchers conducted an interventional study using a probiotic, a mixture of probiotics or synbiotics in infants ageing between 0 and 24 months. All original and followup studies were included, without probiotic species or study design restrictions. Both mechanistic studies as well as studies attempting to cure, treat, alleviate or prevent an illness were incorporated into this analysis. A total number of 139 studies describing a probiotic or synbiotic intervention in participants ageing from birth to 18 years were analysed for applicability based on the abstract of the publication. Subsequently, a full text analysis was conducted on 128 studies, as 11 studies could not be accessed or were not published in English. Forty-nine articles were excluded from the safety analysis because not all participants in the intervention arms were between 0 and 24 months of age. An additional six articles were excluded as no probiotic intervention was conducted during the study. Hence, the safety analysis was based on 65 studies, of which 57 and 8 were original and follow-up studies, respectively (Figure 1). The remaining eight papers concerned secondary analyses on previous studies and were therefore excluded from analysis.

The safety profile of the administered probiotics and synbiotics were assessed by means of the reported AEs, and analysed according to their nature and quantity. AEs are defined as the occurrence of complications or illnesses, or worsening of the condition throughout the study. AEs were categorised according to the Common Terminology Criteria for Adverse Events (CTCAE version 4.0, NIH, 2009) classification system (Table 1). The CTCAE divides the AEs into 26 categories and grades according to the severity. This study did not grade the severity of the AEs as these data were missing or difficult to interpret. An extra category 'unspecified' was added, as not all reported AEs could be properly categorised. AEs were not further subdivided into related or serious AEs, because this also depends on the judgement of the investigator and unrelated AEs might be related in a large meta-analysis. In some studies both the mother and infant received probiotic supplements. In these cases, only the AEs reported in the infants were taken into account. Other relevant data, such as probiotic strains, dosage, intervention duration and efficacy, were taken

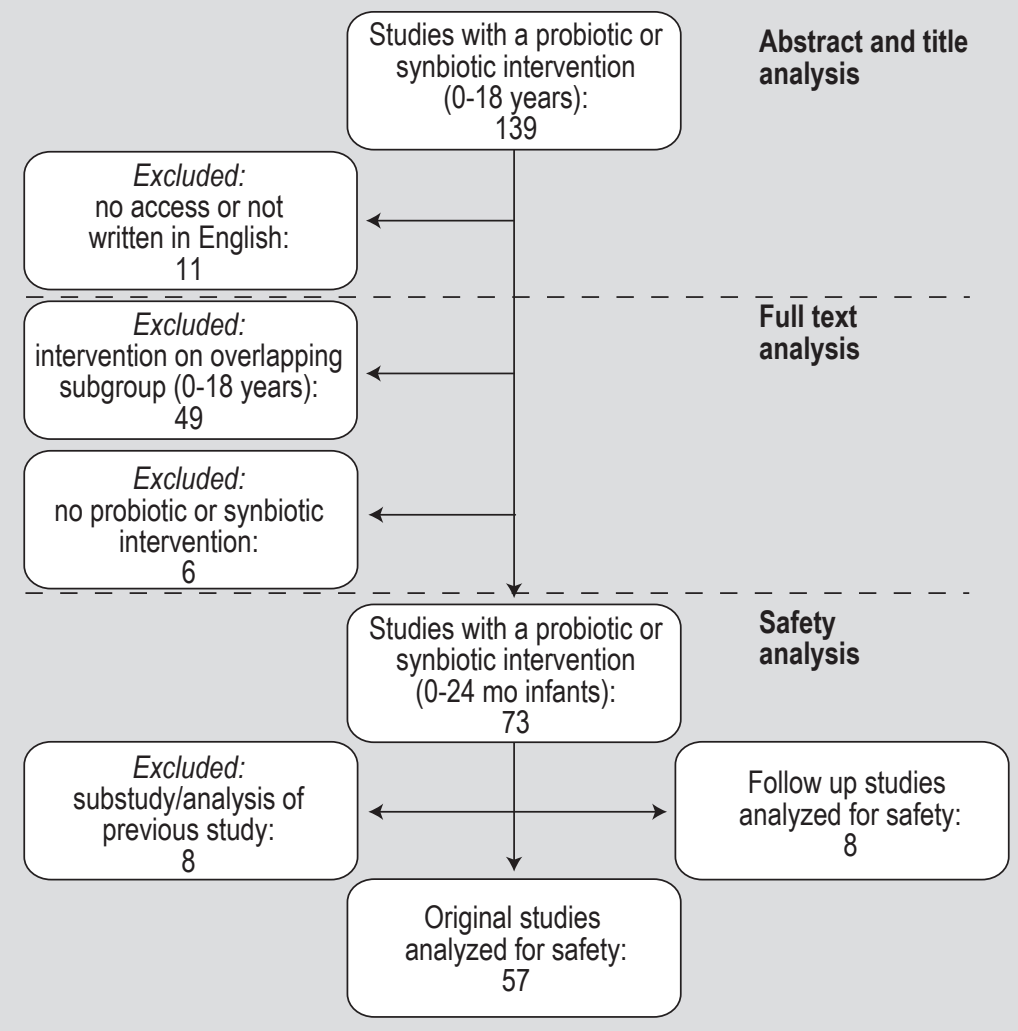

Figure 1. Literature search flow of the safety analysis. 
Table 1. The common terminology clinical adverse events (CTCAE) version 4.0. The CTCAE is a descriptive terminology, which can be utilised for adverse event (AE) reporting according to 26 categories. The $27^{\text {th }}$ category 'unspecified' was added as not all reported AEs could be categorised.

$\begin{array}{ll}\text { Category } & \text { Designation } \\ & \\ \text { Blood and lymphatic system disorders } & \text { I } \\ \text { Cardiac disorders } & \text { II } \\ \text { Congenital, familial and genetic disorders } & \text { III } \\ \text { Ear and labyrinth disorders } & \text { IV } \\ \text { Endocrine disorders } & \text { V } \\ \text { Eye disorders } & \mathrm{VI} \\ \text { Gastrointestinal disorders } & \mathrm{VII} \\ \text { General disorders and administration site conditions } & \mathrm{VIII} \\ \text { Hepatobiliary disorders } & \mathrm{IX} \\ \text { Immune system disorders } & \mathrm{X} \\ \text { Infections and infestations } & \mathrm{XI} \\ \text { Injury, poisoning and procedural complications } & \mathrm{XII} \\ \text { Investigations } & \mathrm{XIII} \\ \text { Metabolism and nutrition disorders } & \mathrm{XIV} \\ \text { Musculoskeletal and connective tissue disorders } & \mathrm{XV} \\ \text { Neoplasms benign, malignant and unspecified (incl cysts } & \mathrm{XVI} \\ \text { and polyps) } & \\ \text { Nervous system disorders } & \mathrm{XVII} \\ \text { Pregnancy, puerperium and perinatal conditions } & \mathrm{XVIII} \\ \text { Psychiatric disorders } & \mathrm{XIX} \\ \text { Renal and urinary disorders } & \mathrm{XX} \\ \text { Reproductive system and breast disorders } & \mathrm{XXI} \\ \text { Respiratory, thoracic and mediastinal disorders } & \mathrm{XXII} \\ \text { Skin and subcutaneous tissue disorders } & \mathrm{XXIII} \\ \text { Social circumstances } & \mathrm{XXIV} \\ \text { Surgical and medical procedures } & \mathrm{XXV} \\ \text { Vascular disorders } & \mathrm{XXVI} \\ \text { Unspecified } & \mathrm{XXVII} \\ & \\ & \end{array}$

into account for additional analyses. It should be noted that this review uses the terms probiotics and synbiotics interchangeably, as the synbiotics contain probiotic strains.

\section{Results}

A total of 10,056 infants, between 0 and 24 months of age, were enrolled in the 57 eligible clinical intervention studies (analysed studies, Table 2). 5,643 infants were assigned to the treatment arm and 4,413 infants to the placebo arm, with a drop-out rate of 10.3 and $10.6 \%$ respectively. The data of the entire allocated population were used in the safety analysis, as these include drop-outs due to AEs, which are not included in the per-protocol population. Most studies were published between 2008 and 2012, whereas only one study was published in 2013. The participants were recruited according to their respective health status or illness, and could be subdivided into the following groups:

\section{Table 2. List of clinical studies evaluated.}

Abrahamsson et al., 2009, 2011

Mohan et al., 2008.

Al-Hosni et al., 2012

Allen et al., 2010

Morisset et al., 2011

Baldassarre et al., 2010

Nermes et al., 2011

Basu et al., 2009

Niers et al., 2009

Braga et al., 2011

Ou et al., 2012

Chouraqui et al., 2008

Chrzanowska-Liszewska et al., 2012

Panigrahi et al., 2008

Rautava et al., 2009

Ritchie et al., 2010

Coccorullo et al., 2010

Dekker et al., 2009

Dutta et al., 2011

Fernández-Carrocera et al., 2012

Rojas et al., 2012

Romeo et al., 2011

Rose et al., 2010

Rougé et al., 2009

Firmansyah et al., 2011

Gibson et al., 2009

Rozé et al., 2012

Salmi et al., 2010

Gil-Campos et al., 2012

Gore et al., 2012

Samanta et al., 2008

Sari et al., 2012

Grandy et al., 2010

Haschke-Becher et al., 2008

Savino et al., 2010

Hascoët et al., 2011

Scalabrin et al., 2009

Soh et al., 2009, 2010

Hol et al., 2008

Holscher et al., 2012

Indrio et al., 2008, 2009, 2011

Szajewska et al., 2013

Taipale et al., 2011, 2012

Teran et al., 2009

Kopp et al., 2008

Kuitunen et al., 2009a,b

Kukkonen et al., 2008, 2011

Larsen et al., 2011

Lin et al., 2008

Lodinová-Žádníková et al., 2010

Underwood et al., 2009

Van der Aa et al., 2010, 2011, 2012

Velaphi et al., 2008

Vlieger et al., 2009

West et al., 2009

Wickens et al., 2012

Yamasaki et al., 2012

Youngster et al., 2011

Manzoni et al., 2009, 2011

Mihatsch et al., 2010

(1) no disorder, including the subgroups healthy, formulafed, caesarean delivered, and at risk of allergy (one or more first degree relatives with an allergic disease) infants; (2) preterm infants, ranging from healthy to very low birth weight ( $<1,500 \mathrm{~g})$; (3) infants suffering from intestinal disorders, which could be subdivided into the subgroups diarrhoea, infantile colic, chronic constipation and regurgitation; and (4) inflammatory disorders, encompassed atopic dermatitis, eczema and cow's milk allergy.

As illustrated in Figure 2, the majority of infants received $L$. rhamnosus GG. In general, L. rhamnosus GG, Lactobacillus reuteri DSM 17938, L. rhamnosus LPR and Bifidobacterium longum BL999 were each administered to at least 450 participants. The strains Bifidobacterium lactis BB-12, B. bifidum CUL20, B. bifidum NCDO 1453, B. lactis CUL34, Lactobacillus acidophilus NCDO 1748, Lactobacillus paracasei CUL08 and Lactobacillus salivarius CUL61 were supplemented to between 200 and 450 participants each. Between 100 and 200 participants received the 

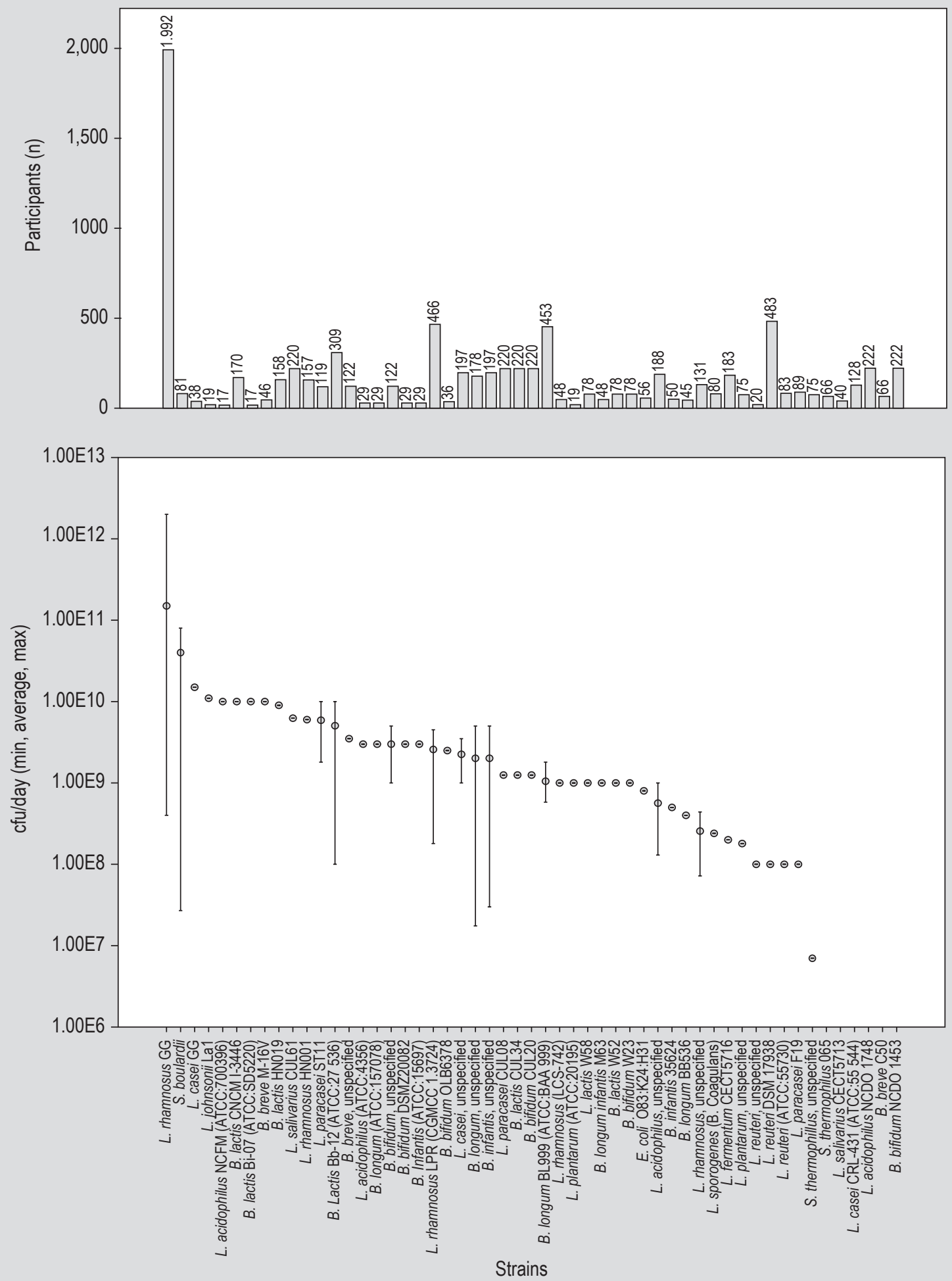

Figure 2. The range of daily cfu intake and participants for each probiotic strain.

probiotic strains Bifidobacterium infantis (unspecified), Lactobacillus casei (unspecified), L. acidophilus (unspecified), Lactobacillus fermentum CECT5716, $B$. longum (unspecified), B. lactis CNCM I-3446, B. lactis HN019, L. rhamnosus HN001, L. rhamnosus (unspecified),
L. casei CRL-431 (ATCC:55 544), B. bifidum (unspecified), L. paracasei ST11 and Bifidobacterium breve (unspecified). The other probiotic strains were administered to less than 100 participants, making their safety data less reliable. Probiotic species lacking proper strain designation is due 
to incomplete intervention description in the original studies. Figure 2 demonstrates the evaluated daily dosage for each probiotic culture depicted as minimal, maximal and average dosage in cfu. On average, the infants received a total of $2.79 \times 10^{10} \mathrm{cfu} /$ day $\left(4.23 \times 10^{9} \mathrm{cfu}\right.$ without the two outliers), ranging from a maximal dosage of $2 \times 10^{12} \mathrm{cfu}$ with L. rhamnosus GG to the lowest dosage of $7 \times 10^{6} \mathrm{cfu}$ with S. thermophilus (unspecified). The strains L. rhamnosus GG, L. rhamnosus LPR (CGMCC 1.3724), B. longum BL999 (ATCC:BAA 999), B. lactis Bb-12 (ATCC:27 536), B. infantis, L. casei, L. acidophilus, B. longum, L. rhamnosus, B. bifidum, Saccharomyces boulardii and L. paracasei ST11 were evaluated for multiple dosages, whereas the other strains were only assessed at a single dosage or the daily applied cfu dosage was missing. As literature did not indicate a clear daily cfu dosage, data are missing for the strains B. bifidum NCDO 1453, L. acidophilus NCDO 1748, L. casei CRL-431 (ATCC:55 544), B. breve C50, S. thermophilus 065 and L. salivarius CECT5713.

As not all health conditions or disorders require the same treatment strategy, particular conditions require specific probiotic properties and strains. Nevertheless, most studies administered L. rhamnosus, regardless of the infant's health status, except for infants with an immunologic disorder; the majority of these infants received B. lactis. In preterms and infants with gastrointestinal disorders, $L$. reuteri was the second most frequent studied probiotic, whereas for healthy infants and infants with an immune disorder this was B. lactis and L. casei, respectively. When analysing on a specific strain basis, $L$. rhamnosus GG is evaluated in the majority of studies. However, in healthy infants, this is not the most investigated probiotic strain, as the majority of participants received B. longum BL999 $(\mathrm{n}=580)$. Figure 3 depicts the number of participants for each probiotic strain and the total number of studies performed using this strain, analysed for (a) healthy and (b) preterms infants.

Analysis of the study durations is depicted in Figure 4A. The mean intervention duration for the 57 trials was 121 days. Three studies did not define a clear study duration, but rather a clinical outcome as endpoint; hence, these studies were not being included in this analysis. The majority of the participants were exposed to probiotics, during a period of 6 months or shorter (46 studies). Only one study evaluated the effect of long-term exposure, as the participants received probiotics for 2 years. Infants suffering from diarrhoea had the shortest exposure (mean 5 days), whereas the infants at risk of developing an allergy received the study product during a mean of 266 days. The mean study duration for healthy and formula-fed infants was also more than 4 months.

Studies were analysed for the non-specific overall safety statement, independently of the reported AEs. These safety statements ranged from 'no AEs were reported during the intervention' and 'the study product was well tolerated' to 'increased complications'. As stated in Figure 4B, 28 and $26 \%$ of the studies did not encounter any AEs or the AEs were not related to the study product, respectively. There was no significant difference in AEs between the treatment arm and the placebo arm in $12 \%$ of the studies, and $11 \%$ of the studies stated that the investigational product was well tolerated. Notably, $21 \%$ of the studies did not discuss or report AEs or any safety aspects. One study $(2 \%)$ reported increased complications due to probiotic administration (Gore et al., 2012).

The administered dosage per condition is depicted in Figure $5 \mathrm{~A}$. The highest daily dosage range is applied to infants suffering from diarrhoeal disease; $2 \times 10^{7}$ to $2 \times 10^{12} \mathrm{cfu}$. Infants suffering from other gastrointestinal disorders, such as regurgitation and constipation, received on average the lowest cfu per day. Surprisingly, all formula-fed infants received a total of $1 \times 10^{10} \mathrm{cfu}$ per day. The lowest daily dosage of $7 \times 10^{6}$ was administered to preterm (low-birthweight) infants, however they were exposed to an average of $2 \times 10^{9}$ cfu per day.

Data from the follow-up studies did not indicate any safety concerns. A 10-year follow-up study by Luoto et al. (2010) reported no AEs or any effect on growth pattern and development of obesity by L. rhamnosus GG. Van der Aa et al. (2011) demonstrated that, after a follow-up period of one year, infants receiving $B$. breve $\mathrm{M}-16 \mathrm{~V}$ had less asthma-like symptoms compared to the placebo group. In addition, Kukkonen et al. (2008) showed that a mix of probiotics is safe on the long-term and increased resistance to respiratory infections.

The number of participants allocated and analysed 'per protocol' for each infant health condition is shown in Figure $6 \mathrm{~A}$. The majority of infants subjected to an intervention were preterms, infants at risk of allergy and healthy infants, respectively. The most common reported AEs were 'diarrhoea,' 'respiratory infections', 'gastrointestinal infections', 'sepsis' and 'fever'. Please note that this in itself is not surprising, since these effects were also the main clinical outcomes to be influenced by probiotics. However, in view of $\mathrm{AE}$ reporting this should not induce a bias in properly conducted studies. A total of 5,147 AEs were reported in the treatment and placebo group together. AEs in the category of infections and infestations (category XI) occurred most frequently, followed by gastrointestinal symptoms (category VII), respiratory, thoracic and mediastinal disorders (category XXII), and general disorders and administration site conditions, such as fever (category VIII). Figure 6B shows the distribution of AEs for the various CTCAE categories for all probiotic intervention arms and non-probiotic control arms. The AEs that occurred in the other categories were relatively rare. When focussing more closely on reported AEs within the 
A

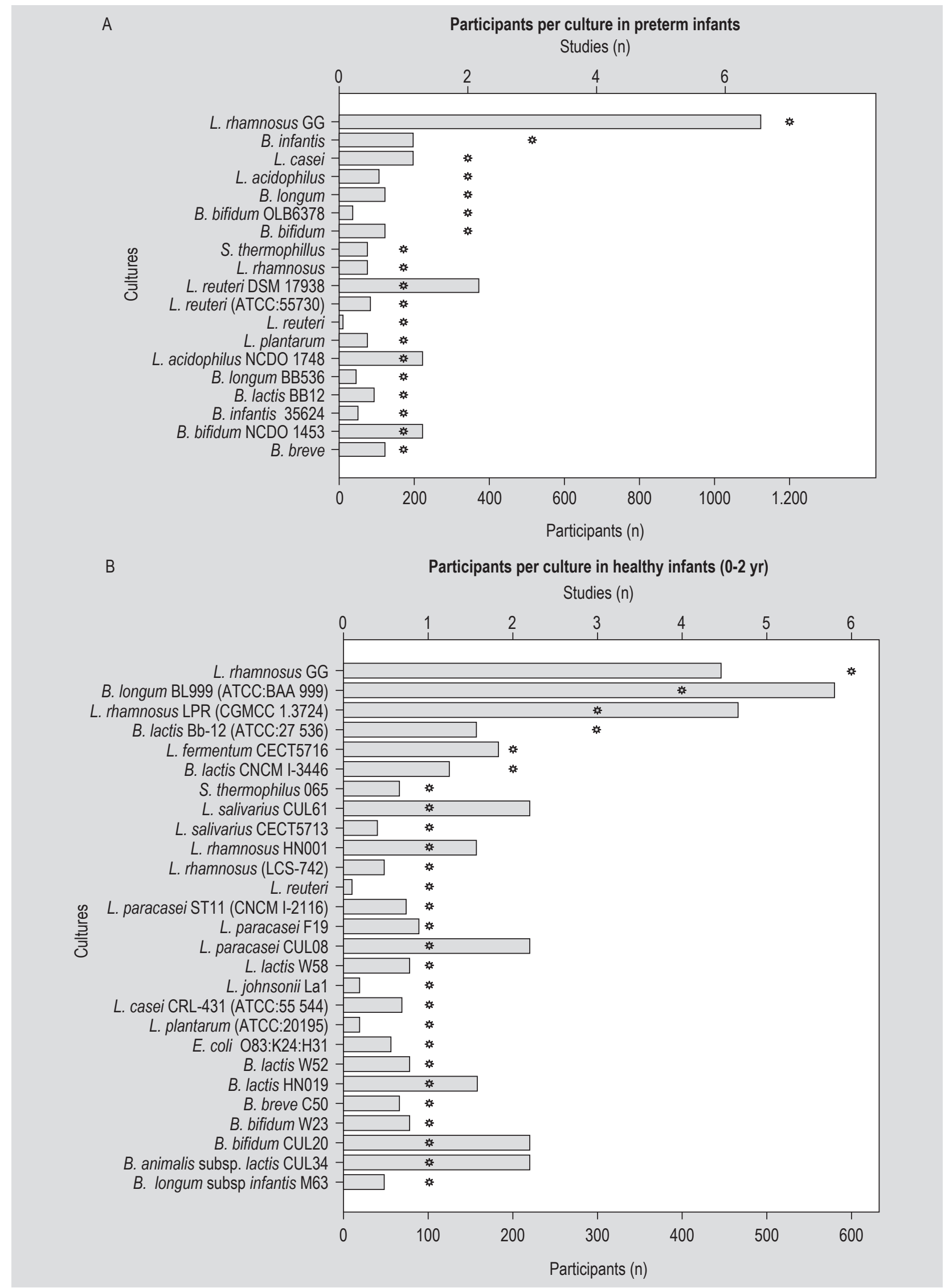

Figure 3. Participants and number of studies per culture in (A) preterm and (B) healthy infants. The gray bar represents the number of participants, the asterisk is the number of studies. 
A

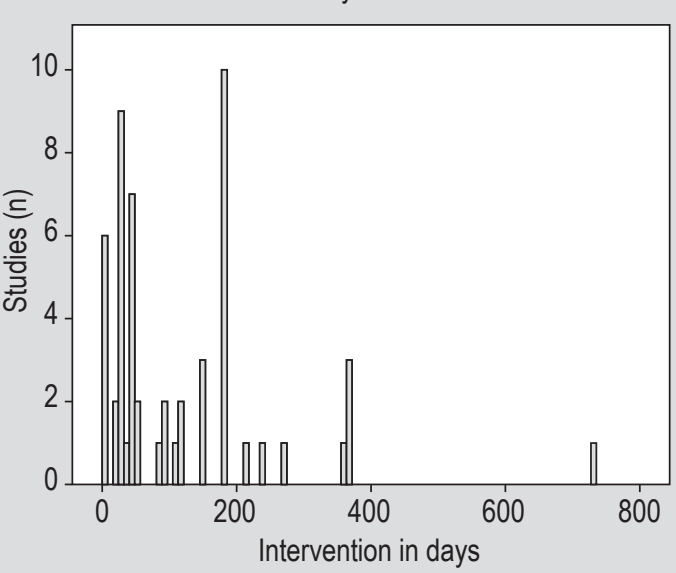

B

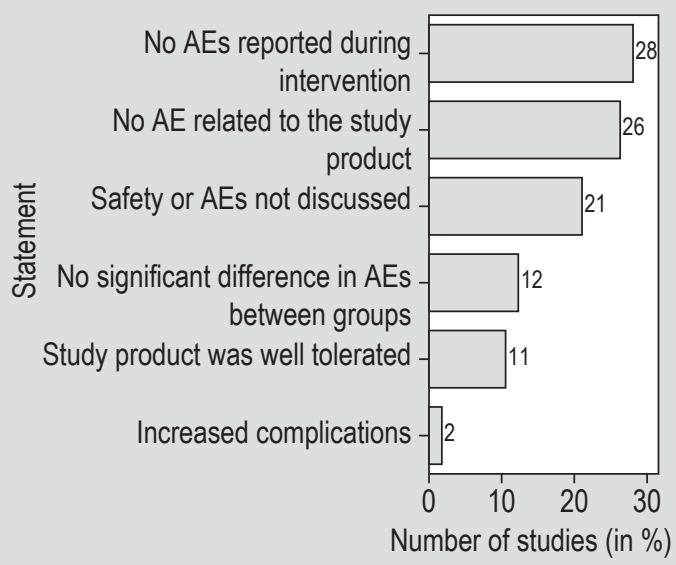

Figure 4. Histogram of (A) duration of each study in days and (B) the percentage of studies reporting a general safety statement. $\mathrm{AEs}=$ adverse events.

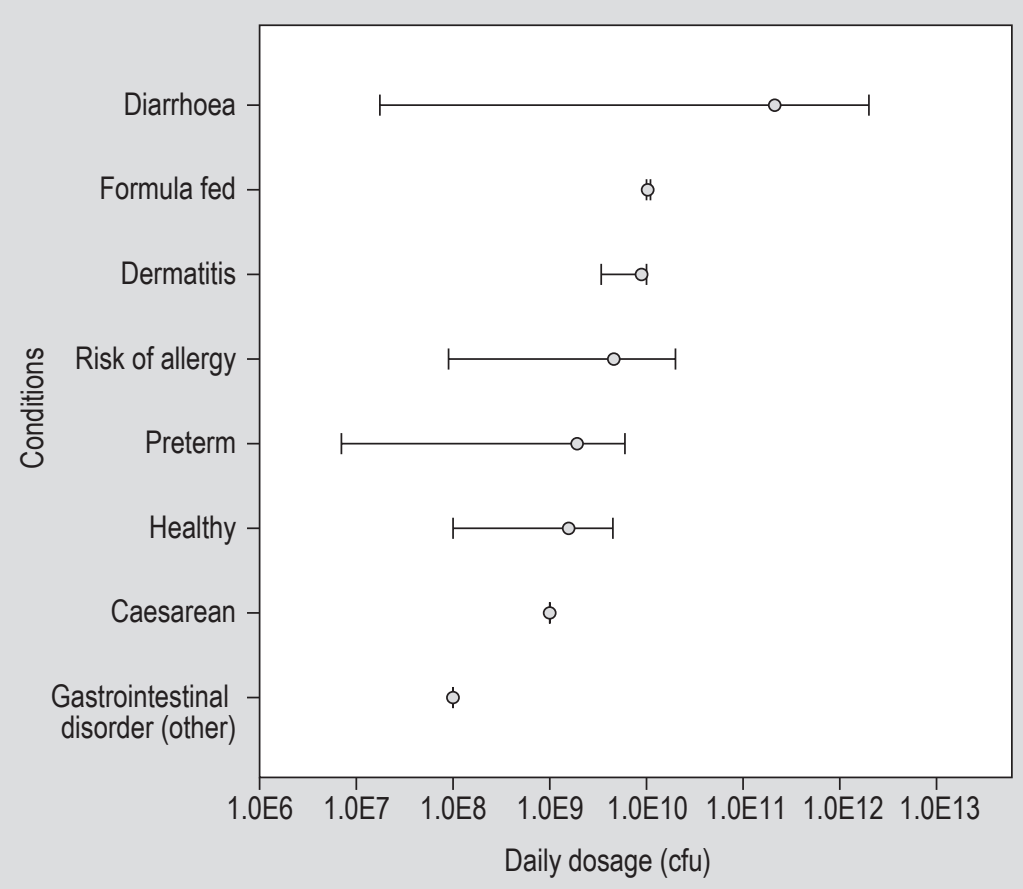

Figure 5. Range of evaluated interventional dose per day for each infant health status; minimal, average and maximal cfu per day. Condition 'other' entails cow's milk allergy and vaccinated infants.

specific infant conditions, infections and infestations (XI) are most prevalent in preterm infants. In category XI, 100 more AEs were reported in the treatment arm compared to the control group. The incidence of gastrointestinal symptoms was lower in the verum group (Figure 6C). In infants suffering from diarrhoea, more AEs are reported in the treatment group for all CTCAE categories, although the number of AEs is very low compared to the number of allocated participants (Figure 6D). When focussing on reported AEs in infants with dermatitis, eye disorders
(VI), gastrointestinal symptoms (VII) and immune system disorders (X), AEs are more frequently observed in treatment group compared to the placebo group, whereas skin and subcutaneous tissue disorders (XXIII) were less frequently reported in the treatment group (Figure 6E). In formula-fed infants, all AEs occurred more frequently in the control group, with the highest prevalence of infections and infestations (XI) (Figure 6F). In the healthy infant population, infections and infestations were most commonly observed, whereas in infants at-risk of developing an allergy, 
A Participants allocated and analyzed per condition

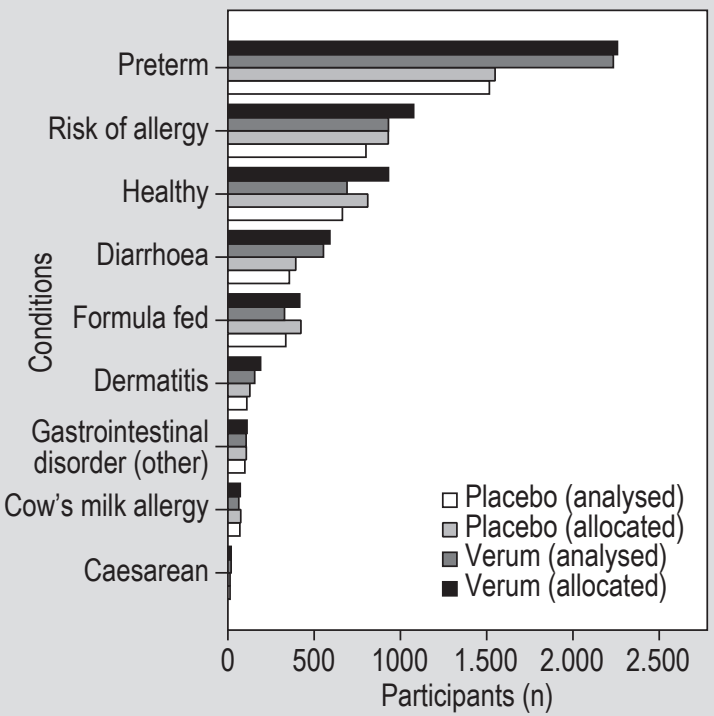

C AEs preterm infants (low-birth-weight)

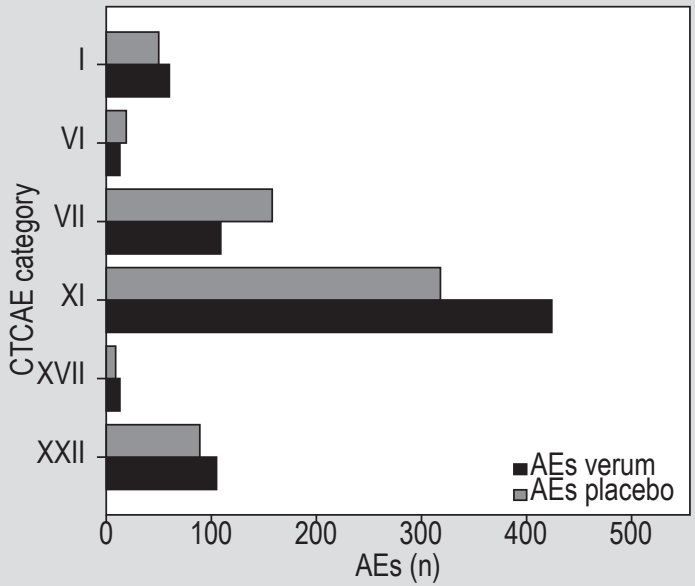

E AEs infants with dermatitis (0-2 yr)

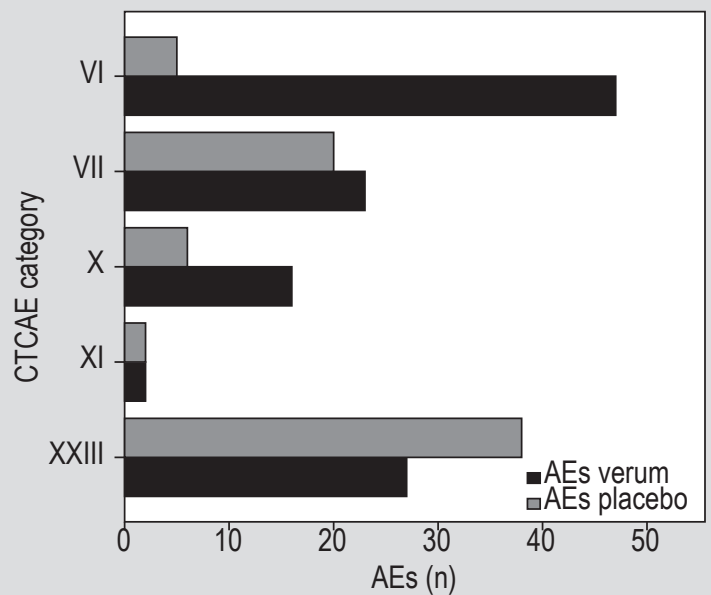

B

Total AEs reported in infants $(0-2 \mathrm{yr})$

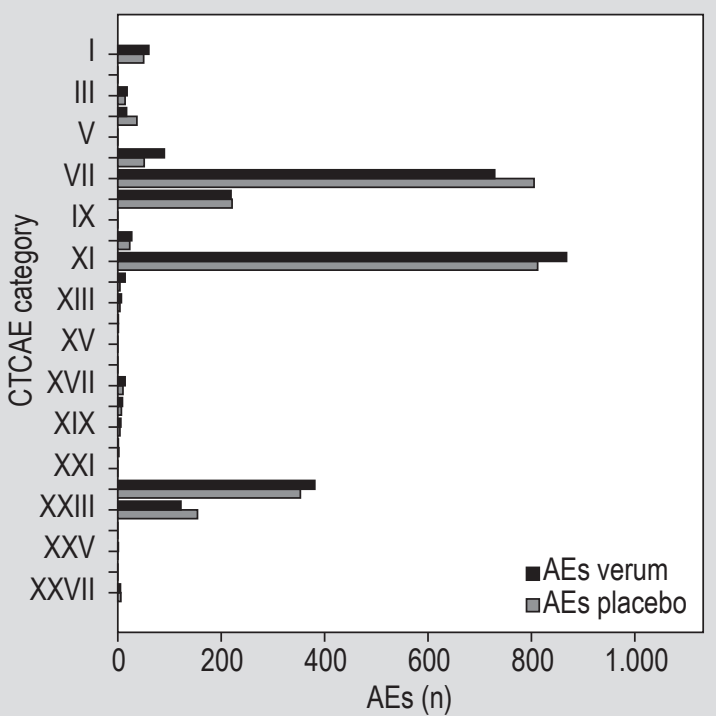

D

AEs infants with diarrhea (0-2 yr)

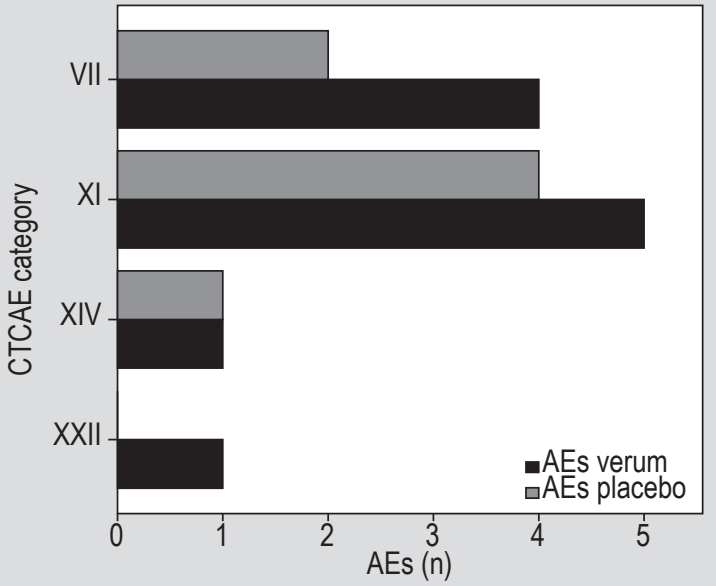

F

AEs formula-fed infants (0-2 yr)

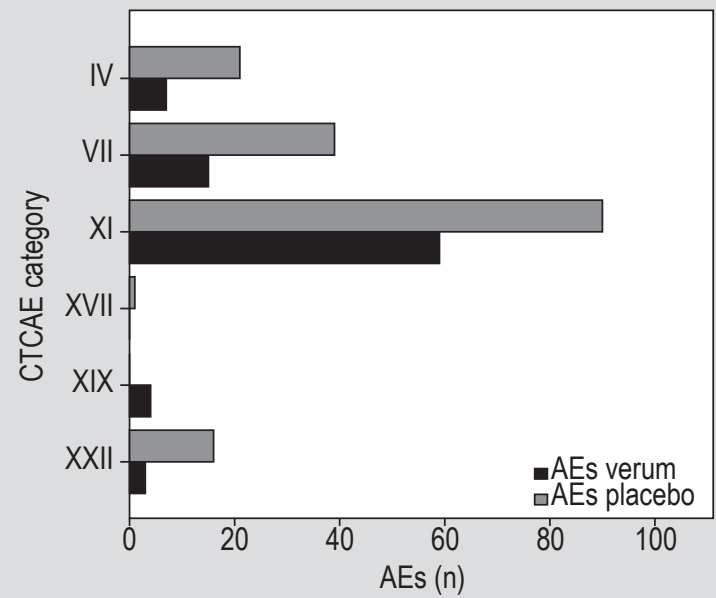

Figure 6. (A) Participants allocated and analysed per protocol of the verum and placebo group for each health condition. (B) The total adverse events (AEs) reported of all studies, comparing placebo and verum group and categorised according to the Common Terminology Clinical Adverse Events (CTCAE). (C) Reported AEs categorised according to CTCAE analysed for preterm infants, (D) infants with diarrhoea, (E) infants with dermatitis, and (F) formula-fed infants. 
gastrointestinal symptoms (VII) occurred more frequently. In addition, the incidence of AEs that could be categorized as gastrointestinal symptoms (VII, 207 and 180), fever episodes (VIII, 189 and 186) and respiratory, thoracic and mediastinal disorders (XXII) were high ( $\mathrm{n}=226$ and 197 for the treatment and placebo, respectively) in healthy infants. In infants affected by gastrointestinal disorders other than diarrhoea, few AEs were reported and often of gastrointestinal of nature (data not shown).

\section{Discussion and conclusions}

Analysis of the 57 clinical trials with probiotics and synbiotics in combination with eight follow-up studies, published between 2008 and 2013, indicate that probiotic administration to infants between 0 and 24 months is safe with regard to the evaluated strains in infants with a particular health status or susceptibility. Most AEs and serious AEs were considered unrelated to the study product, and there were no major safety concerns. Almost all studies concluded that none of the AEs were related to the study product and the study products are generally well tolerated. Only a single study reported increased complications, such as green loose stools, increased vomiting, feed-refusal or colic, although, prevalence and significance of AEs was not described (Gore et al., 2012). This study analysed whether dietary supplementation of infants with eczema at age 3-6 months with probiotics had a treatment effect or altered allergic disease progression. These infants ingested $L$. paracasei CNCM I-2116 or B. lactis CNCM I-3446 in combination with an extensively hydrolysed (EH) infant formula. This EH-infant formula could well have induced the AEs, as other studies using L. paracasei CNCM I-2116 and B. lactis CNCM I-3446 do not report any significant AEs (Chouraqui et al., 2008; Gibson et al., 2009; Velaphi et al., 2008). Gore and colleagues did also not report any significant clinical effect between the study groups, whereas previous studies analysing the effect of other probiotics in infants with eczema demonstrate a positive clinical results and no AEs (Weston et al., 2005; Rosenfeldt et al., 2003).

The data of this review indicate that there is no significant difference in the number of AEs between the probiotic and the control group; both in the total population as well as in the specific health conditions. A total of 2,589 and 2,558 AEs were reported in the treatment and control group, respectively. This subtle difference of 31 more AEs in the treatment arm is not significant as 1,230 more participants were allocated to this arm and hence relatively more AEs occurred in the control group (incidence rate of an $\mathrm{AE}=0.458$ in the treatment group vs. 0.579 in the placebo group, respectively). The largest difference in participant allocation between treatment and placebo group was observed in the preterm study population. This deviation could be attributed to the retrospective study of Manzoni et al. (2011), analysing the effect of L. rhamnosus
GG supplementation in preterm infants. This study did not include a control group, which explains the higher observed frequency of AEs. In particular, Manzoni et al. (2011) documented 142 cases of late-onset sepsis, in the category infections and infestations (XI). This explains that more AEs are observed in the probiotic group in category (XI). If these cases were subtracted from the total reported AEs in category XI, 86 more infections and infestations occurred in the control group. This would be consistent with other reports in the literature indicating that probiotics reduce the incidence of infections (Maldonado et al., 2012; Manzoni et al., 2009; Taipale et al., 2011).

Despite that 984 infants with diarrhoea were allocated to the treatment or control arm, surprisingly very few (18) AEs were reported in these studies. A proportion of these infants received a very high daily dosage of $2 \times 10^{12}$ cfu L. rhamnosus GG, with no significant difference in AEs (Basu et al., 2009). These data are encouraging and further underpin the evidence that $L$. rhamnosus GG is safe in infants, even at a very high dosage. The strain $L$. rhamnosus GG is well characterised and evaluated in a large population sample at varying dosages. Unfortunately, this is not the case for many other potential beneficial probiotic strains. For many infant health conditions, daily intake did not exceed $1 \times 10^{10} \mathrm{cfu}$. Especially in healthy infants, the range of administrated dosage is relatively narrow, and these infants are the least susceptible for complications compared to other health conditions. Examining higher probiotic exposure in this healthy group could facilitate the establishment of the optimal dosage for infants.

In infants affected by dermatitis, the number of AEs in the category eye disorders (VI) and allergies (X) were substantially higher in the treatment group compared to placebo. This was mainly due to the study by Gore $e t a l$. (2012) that observed significantly more frequently itchy and red eyes at the age of 12 months in the probiotic group. However this significant difference was not persistent at later visits. Whether this is due to the EH-infant formula or the probiotic strains should still be determined.

Despite the large number of reported AEs in the clinical trials, only 21 studies observed a significant difference in AEs between the treatment and control arm. In most of these cases, probiotic treatment had a protective effect; in the control groups the frequencies of the occurred AEs were significantly higher. Despite these encouraging results, there were some safety concerns. Scalabrin et al. (2009) reported excessive crying in formula-fed infants and Kopp et al. (2008) observed a significant higher incidence of recurrent wheezing bronchitis in infants at risk of allergy after $L$. rhamnosus GG supplementation. Although a significant safety concern, this only occurred in a small sample $(n=54)$ and was not observed in any other analysed clinical study with $L$. rhamnosus GG. In contrast to the other clinical 
trials, probiotic administration of B. longum BL999 and L. rhamnosus LPR induced more episodes of diarrhoea in healthy infants compared to placebo (Firmansyah et $a l ., 2011)$. This increase in diarrhoea might be due to the fructose-oligosaccharide or other prebiotic additives in the study product, which were not present in the control product. The majority of analysed studies do not indicate any difference in respiratory tract infections between either intervention arms, or even demonstrate a slight protective effect against respiratory tract infections. Nevertheless, Allen et al. (2010) observed a higher frequency of lower respiratory tract infections when exposed to a probiotic mixture of L. salivarius CUL61, L. paracasei CUL08, Bifidobacterium animalis subsp. lactis CUL34 and $B$. bifidum CUL20.

No study reported a bacteraemia or fungemia associated with the ingested probiotics. This is in line with the literature. Since 1980s, there has been no increase in frequency of Lactobacillus associated bacteraemia cases in Finland, despite a substantial increase in probiotic use (Salminen et al., 2002). Clinical infections, such as bacteraemia and myocarditis, are rarely (over a period of 10 years covering an population of 1.3 million persons where probiotics are standard in the diet; Salminen et al., 2002) associated with the use of the probiotics Lactobacillus or Bifidobacterium. Also in a large study (in subjects with severe underlying disease!) evaluating 89 cases of Lactobacillus bacteraemia (unrelated to probiotic intake) treatment with antimicrobials was effective both in vitro and in reducing mortality (odds ratio $=0.22$; Salminen $e t$ $a l ., 2004)$. In another very large survey, only 12 cases of bacteraemia were reported concurrent with the use of $L$. rhamnosus GG, 5 cases with Bacillus subtilis and 1 case with L. acidophilus. There were only 27 reports of fungemia when the yeast $S$. boulardii concurrently was administered, and the authors concluded probiotics are safe but results cannot be generalised for other or new/future strains (Boyle et al., 2006).

Although the primary goal was not to identify the efficacy of probiotic interventional studies, most studies reported a significant beneficial clinical outcome effect. Increased stool frequency, softer stools and reduced diarrhoea were among the most common clinical effects. Despite the limited overall effects, in specific health conditions, such as preterms and infants suffering from diarrhoea, results are more promising; probiotics seem to prevent NEC (Bell's stage II and higher) and reduce the duration and hospitalisation in diarrhoea (Fernández-carrocera et al., 2012; Grandy et al., 2010; Lin et al., 2008; Teran et al., 2009). Nevertheless, 11 studies did not report any significant effect in the treatment arm compared to the control group, thereby maintaining the controversy of probiotic efficacy. Large meta-analyses should provide overall benefit/risk analyses and conclusions, and underpin policies for implementation of probiotic treatment.

Based on the study by Hempel et al. (2011) combined with the current data, we still cannot provide a decisive safety profile of probiotics and synbiotics. The documentation of the clinical studies is poor, as they lack details regarding AEs, the specific identity of probiotic strains and administered dosage. Very few studies address specifically probiotic complications and are not designed to assess the safety profile. Additionally, safety should be evaluated on a strainby-strain basis, depending on long-term and high dosage exposure.

A major pitfall of this safety analysis is the lack of consistent AE reporting. Many studies do not provide the incidence of AE, however, only state that 'no significant difference in complications was observed between the study groups'. Studies fail in particular to report the frequency of more common AEs, such as diarrhoea, vomiting, regurgitation, fever and flatulence, and focus more on irregular AEs. Incidences of serious AEs are often not well described and designated as unrelated to the study product, while large meta-analyses could give new insight in the causal relation of $\mathrm{AE}$ and the use of probiotics. The lack of this data inhibits a clear overview of the incidence of real complications and explains potential underrepresentation of certain CTCAE categories.

Another major flaw is the incorrect documentation of probiotic strains. Probiotics should be properly characterised according to the taxonomy, including specific strain and culture. Many studies fail to do this. Since beneficial effects on the host can only be attributed to a specific culture, selecting the correct probiotic strain is essential. Even if bacteria share the same genus and species, their properties can differ significantly and thus need to be tested individually (Van Baarlen et al., 2011). Another shortcoming is that not all studies provide and mention a clear daily dosage (cfu) and duration of intervention. Studies that administer infant formula supplemented with probiotics do indicate the $\mathrm{cfu} / \mathrm{g}$; however, they fail to indicate the ingested $\mathrm{cfu} /$ day. A minimal concentration of probiotics is necessary to gain successful colonisation, which is often transient of nature (Petschow et al., 2005). This missing data prevents the establishment of an optimal dose-response relationship. A higher probiotic dosage could induce a higher incidence of AEs. This review shows that the ranges of evaluated dosages are narrow for many infant conditions, and few studies administered probiotics at very high dosages. Research should focus on the efficacy of a single probiotic, a probiotic mixture or synbiotics. To obtain reliable data, studies should be well designed to test efficacy, preferably randomised, placebo controlled, double blinded studies. It is of importance that the probiotics or synbiotics have a well-defined target population. By 
evaluating safety and efficacy on subgroups, including high-risk groups, the beneficial health effects can only be attributed to specific probiotic strains and for a certain health status. Investigators and industry should be aware that strain specific safety and efficacy data on particular patient populations should not be extrapolated to other probiotic strains or target populations.

\section{Recommendations}

Based on the probiotic format, target indication and mode of administration, a probiotic product can be characterised as a food, food supplement, biological or pharmaceutical product. These products are all subject to different regulations, which complicates safety guidelines and health claims. If probiotic products are used to prevent, treat, or alleviate a medical condition, the product should be considered as a biological product and evaluated according to the International Conference on Harmonisation of Technical Requirements - Good Clinical Practice and medical product procedures to produce consistent safety and efficacy data. This includes detailed descriptions of the studied product, and a comprehensive $\mathrm{AE}$ documentation.

Each new probiotic strain should be analysed for properties, including genomics, to understand the mode of action. Metabolic mechanisms, interaction with the host immunity and ability to exchange virulence factors with pathogens is essential for a comprehensive safety profile. Even if the probiotic strain is considered safe, it can still become opportunistic and cause bacteraemia. Probiotics should be considered safe if they at least fulfil the following specific criteria: (a) the probiotic strain should be properly isolated and classified according to the correct taxonomy; (b) manufactured according to good manufacturing practices to eliminate contamination with other microbes, probiotics or substances; (c) a clear overview of the safety (according to standardised and accepted CTCAE) and toxicity levels associated with the probiotic administration; and (d) a clear evaluation of the target population, including high risks groups such as infants and immune deficient patients.

\section{Acknowledgements}

We would like to thank Joop Orsouw for optimisation of the figures.

\section{References}

Abrahamsson, T.R., Sandberg Abelius, M., Forsberg, A., Björkstén, B. and Jenmalm, M.C., 2011. A Th1/Th2-associated chemokine imbalance during infancy in children developing eczema, wheeze and sensitization. Clinical and Experimental Allergy 41: 1729-1739.
Abrahamsson, T.R., Sinkiewicz, G., Jakobsson, T., Fredrikson, M. and Björkste, B., 2009. Probiotic Lactobacilli in breast milk and infant stool in relation to oral intake during the first year of life. Journal of Pediatric Gastroenterology and Nutrition 49: 349-354.

Al-Hosni, M., Duenas, M., Hawk, M., Stewart, L.A., Borghese, R.A., Cahoon, M., Atwood, L., Howard, D., Ferrelli, K. and Soll, R., 2012. Probiotics-supplemented feeding in extremely low-birth-weight infants. Journal of Perinatology 32: 253-259.

Allen, S.J., Jordan, S., Storey, M., Thornton, C.A., Gravenor, M., Garaiova, I., Plummer,S.F., Wang,D. and Morgan, G., 2010. Dietary supplementation with lactobacilli and bifidobacteria is well tolerated and not associated with adverse events during late pregnancy and early infancy. Journal of Nutrition 140: 483-488.

Alonso, V.R. and Guarner, F., 2013. Linking the gut microbiota to human health. British Journal of Nutrition 109: S21-S26.

Baldassarre, M.E., Laforgia, N., Fanelli, M., Laneve, A., Grosso, R. and Lifschitz, C., 2010. Lactobacillus GG improves recovery in infants with blood in the stools and presumptive allergic colitis compared with extensively hydrolyzed formula alone. Journal of Pediatrics 156: 397-401.

Basu, S., Paul, D.K., Ganguly, S., Chatterjee, M. and Chandra, P.K., 2009. Efficacy of high-dose Lactobacillus rhamnosus GG in controlling acute watery diarrhea in Indian children: a randomized controlled trial. Journal of Clinical Gastroenterology 43: 208-213.

Boyle, R.J., Robins-Browne, R.M. and Tang, M.L., 2006. Probiotic use in clinical practice: what are the risks?. The American Journal of Clinical Nutrition 83: 1256-1264.

Braga, T.D., Pontes da Silva, G.A., Cabral de Lira, P.I. and De Carvalho Lima, M., 2011. Efficacy of Bifidobacterium breve and Lactobacillus casei oral supplementation on necrotizing enterocolitis in verylow-birth-weight preterm infants: a double-blind, randomized, controlled trial. American Journal of Clinical Nutrition 93: 81-86.

Chouraqui, J.P., Grathwohl, D., Labaune, J.M., Hascoet, J.M., de Montgolfier, I., Leclaire, M., Giarre, M. and Steenhout, P., 2008. Assessment of the safety, tolerance, and protective effect against diarrhoea of infant formulas containing mixtures of probiotics or probiotics and prebiotics in a randomized controlled trial. American Journal of Clinical Nutrition 87: 1365-73.

Chrzanowska-Liszewska, D., Seliga-Siwecka, J. and Kornacka, M.K., 2012. The effect of Lactobacillus rhamnosus GG supplemented enteral feeding on the microbiotic flora of preterm infants-double blinded randomized control trial. Early Human Development 88: 57-60.

Claassen, E., Essbai, J., Rutgers, T. and Van Deventer, S., 2010. How safe are probiotics? Part 2: Literature. Available at: www.infectieziektenplatform.nl/specialisme/hepatitis/33111.

Clemente, J.C., Ursell, L.K., Wegener Parfrey, L. and Knight, R., 2012. The impact of the gut microbiota on human health: an integrative view. Cell 148: 1258-1270.

Coccorullo, P., Strisciuglio, C., Martinelli, M., Miele, E., Greco, L. and Staiano, A., 2010. Lactobacillus reuteri (DSM 17938) in infants with functional chronic constipation: a double-blind, randomized, placebo-controlled study. Journal of Pediatrics 157: 598-602. 
De Groote, M.A., Frank, D.N., Dowell, E., Glode, M.P. and Pace, N.R., 2005. Lactobacillus rhamnosus GG bacteremia associated with probiotic use in a child with short gut syndrome. Pediatric Infectious Disease Journal 24: 278-280.

De Vrese, M. and Schrezenmeir, J., 2008. Probiotics, prebiotics, and synbiotics. Advances in Biochemical Engineering/Biotechnology 111: 1-66.

Dekker, J.W., Wickens, K., Black, P.N., Stanley, T.V., Mitchell, E.A., Fitzharris, P., Tannock, G.W., Purdie, G. and Crane, J., 2009. Safety aspects of probiotic bacterial strains Lactobacillus rhamnosus HN001 and Bifidobacterium animalis subsp. lactis HN019 in human infants aged 0-2 years. International Dairy Journal 19: 149-154.

Dutta, P., Mitra, U., Dutta, S., Rajendran, K., Saha, T.K. and Chatterjee, M.K., 2011. Randomised controlled clinical trial of Lactobacillus sporogenes (Bacillus coagulans), used as probiotic in clinical practice, on acute watery diarrhoea in children. Tropical Medicine and International Health 16: 555-561.

Fernández-Carrocera, L.A., Solis-Herrera, A., Cabanillas-Ayón, M., Gallardo-Sarmiento, R.C., García-Pérez, C.S., Montaño-Rodríguez, R. and Echániz-Aviles, M.O.L., 2012. Double-blind, randomised clinical assay to evaluate the efficacy of probiotics in preterm newborns weighing less than $1500 \mathrm{~g}$ in the prevention of necrotising enterocolitis. Archives of Disease in Childhood Fetal Neonatal Edition 98: F5-F9.

Firmansyah, A., Dwipoerwantoro, P.G., Kadim, M., Alatas, S., Conus, M., Lestarina, L., Bouisset, F. and Steenhout, P., 2011. Improved growth of toddlers fed a milk containing synbiotics. Asia Pacific Journal of Clinical Nutrition 20: 69-76.

Food and Agriculture Organization of the United Nations (FAO), 2001. Health and nutritional properties of probiotics in food including powder milk with live lactic acid bacteria. Available at: http://www. who.int/foodsafety/publications/fs_management/en/probiotics.pdf.

Ganguli, K. and Walker, W.A., 2011. Probiotics in the prevention of necrotizing enterocolitis. Journal of Clinical Gastroenterology 45: S133-S138.

Gibson, R.A., Barclay, D., Marshall, H., Moulin, J., Maire, J. and Makrides, M., 2009. Safety of supplementing infant formula with long-chain polyunsaturated fatty acids and Bifidobacterium lactis in term infants: a randomised controlled trial. British Journal of Nutrition 101: 1706-1713.

Gil-Campos, M., López, M.A., Rodriguez-Beníteza, M.V., Romero, J., Ronceroa, I., Linares, M.D., Maldonado, J., López-Huertas, E., Berwind, R., Ritzenthaler, K.L., Navas, V., Sierra, C., Sempere, L., Geerlings, A., Maldonado-Lobón, J.A., Valero, A.D., Lara-Villoslada, F. and Olivares, M., 2012. Lactobacillus fermentum CECT 5716 is safe and well-tolerated in infants of 1-6 months of age: a randomized controlled trial. Pharmacological Research 65: 231-238.

Goldenberg, J.Z., Ma, S.S.Y., Saxton, J.D., Martzen, M.R., Vandvik, P.O., Thorlund, K., Guyatt, G.H. and Johnston, B.C., 2013. Probiotics for the prevention of Clostridium difficile-associated diarrhoea in adults and children. Cochrane Database of Systematic Reviews: CD006095.

Gore, C., Custovic, A., Tannock, G.W., Munro, K., Kerry, G., Johnson, K., Peterson, C., Morris, J., Chaloner, C., Murray, C.S. and Woodcock, A., 2012. Treatment and secondary prevention effects of the probiotics Lactobacillus paracasei or Bifidobacterium lactis on early infant eczema: randomized controlled trial with follow-up until age 3 years. Clinical and Experimental Allergy 42: 112-122.

Grandy, G., Medina, M., Soria, R., Terán, C.G. and Araya, M., 2010. Probiotics in the treatment of acute rotavirus diarrhoea. A randomized, double-blind, controlled trial using two different probiotic preparations in Bolivian children. BMC Infectious Diseases 10: 253.

Hardy, H., Harris, J., Lyon, E., Beal, J. and Foey, A.D., 2013. Probiotics, prebiotics and immunomodulation of gut mucosal defences: homeostasis and immunopathology. Nutrients 5: 1869-1912.

Haschke-Becher, E., Brunser, O., Cruchet, S., Gotteland, M., Haschke, F. and Bachmann, C., 2008. Urinary D-lactate excretion in infants receiving Lactobacillus johnsonii with formula. Annals of Nutrition and Metabolism 53: 240-244.

Hascoët, J.M., Hubert, C., Rochat, F., Legagneur, H., Gaga, S., EmadyAzar, S. and Steenhout, P.G., 2011. Effect of formula composition on the development of infant gut microbiota. Journal of Pediatric Gastroenterology and Nutrition 52: 756-762.

Hata, D., Yoshida, A., Ohkubo, H., Mochizuki, Y., Hosoki, Y., Tanaka, R. and Azuma, R., 1988. Meningitis caused by Bifidobacterium in an infant. Pediatric Infectious Disease Journal 7: 669-670.

Hempel, S., Newberry, S., Ruelaz, A., Wang, Z., Miles, J.N.V., Suttorp, M.J., Johnsen, B., Shanman, R., Slusser, W., Fu, N., Smith, A., Roth, E., Polak, J., Motala, A., Perry, T. and Shekelle, P.G., 2011. Safety of probiotics to reduce risk and prevent or treat disease. Evidence Report/Technology Assessment No. 200. AHRQ Publication No. 11-E007. Agency for Healthcare Research and Quality, Rockville, MD, USA. Available at: http://www.ahrq.gov/research/findings/ evidence-based-reports/er200-abstract.html\#Report.

Hibberd, P.L. and Davidson, L.E., 2008. Safety of probiotics. AgroFOOD Industry Hi-Tech 19(4): 30-33.

Hickey, L., Jacobs, S.E. and Garland, S.M., 2012. Probiotics in neonatology. Journal of Paediatrics and Child Health 48: 777-783.

Hol, J., Van Leer, E.H.G., Elink Schuurman, B.E.E., De Ruiter, L.F., Samsom, J.N., Hop, W., Neijens, H.J., De Jongste, J.C. and Nieuwenhuis, E.E.S., 2008. The acquisition of tolerance toward cow's milk through probiotic supplementation: a randomized, controlled trial. Journal of Allergy and Clinical Immunology 121: 1448-1454.

Holscher, H.D., Czerkies, L.A., Cekola, P., Litov, R., Benbow, M., Santema, S., Alexander, D.D., Perez, V., Sun, S., Saavedra, J.M. and Tappenden, K.A., 2012. Bifidobacterium lactis Bb12 enhances intestinal antibody response in formula-fed infants: a randomized, double-blind, controlled trial. Journal of Parenteral and Enteral Nutrition 36: S106-S117.

Indrio, F., Riezzo, G., Raimondi, F., Bisceglia, M., Cavallo, L. and Francavilla, R., 2008. The effects of probiotics on feeding tolerance, bowel habits, and gastrointestinal motility in preterm newborns. Journal of Pediatrics 152: 801-806.

Indrio, F., Riezzo, G., Raimondi, F., Bisceglia, M., Cavallo, L. and Francavilla, R., 2009. Effects of probiotic and prebiotic on gastrointestinal motility in newborns. Journal of Physiology and Pharmacology 60 Suppl. 6: 27-31. 
Indrio, F., Riezzo, G., Raimondi, F., Bisceglia, M., Filannino, A., Cavallo, L. and Francavilla, R., 2011. Lactobacillus reuteri accelerates gastric emptying and improves regurgitation in infants. European Journal of Clinical Investigation 41: 417-422.

Kalliomäki, M., Salminen, S., Arvilommi, H., Kero, P., Koskinen, P. and Isolauri, E., 2001. Probiotics in primary prevention of atopic disease: a randomised placebo-controlled trial. The Lancet 357: 1076-1079.

Kamada, N., Chen, G.Y., Inohara, N. and Núñez, G., 2013. Control of pathogens and pathobionts by the gut microbiota. Nature Immunology 14: 685-690.

Kopp, M.V., Hennemuth, I., Heinzmann, A. and Urbanek, R., 2008. Randomized, double-blind, placebo-controlled trial of probiotics for primary prevention: no clinical effects of Lactobacillus GG supplementation. Pediatrics 121: 850-865.

Kuitunen, M., Kukkonen, K. and Savilahti, E., 2009a. Pro- and prebiotic supplementation induces a transient reduction in hemoglobin concentration in infants. Journal of Pediatric Gastroenterology and Nutrition 49: 626-630.

Kuitunen, M., Kukkonen, K., Juntunen-Backman, K., Korpela, R., Poussa, T., Tuure, T., Haahtela, T. and Savilahti, E., 2009b. Probiotics prevent IgE-associated allergy until age 5 years in cesarean-delivered children but not in the total cohort. Journal of Allergy and Clinical Immunology 123: 335-341.

Kukkonen, A.K., Kuitunen, M., Savilahti, E., Pelkonen, A., Malmberg, P. and Mäkela, M., 2011. Airway inflammation in probiotic-treated children at 5 years. Pediatric Allergy and Immunology 22: 249-251.

Kukkonen, K., Savilahti, E., Haahtela, T., Juntunen-Backman, K., Korpela, R., Poussa, T., Tuure. T. and Kuitunen, M., 2008. Longterm safety and impact on infection rates of postnatal probiotic and prebiotic (synbiotic) treatment: randomized, double-blind, placebo-controlled trial. Pediatrics 122: 8-12.

Kunz, A.N., Noel, J.M. and Fairchok, M.P., 2004. Two cases of Lactobacillus bacteremia during probiotic treatment of short gut syndrome. Journal of Pediatric Gastroenterology and Nutrition 38: 457-458.

Larsen, N., Vogensen, F.K., Gøbel, R., Michaelsen, K.F., Al-Soud, W.A., Sørensen, S.J., Hansen, L.H. and Jakobsen, M., 2011. Predominant genera of faecal microbiota in children with atopic dermatitis are not altered by intake of probiotic bacteria Lactobacillus acidophilus NCFM and Bifidobacterium animalis subsp. lactis Bi-07. FEMS Microbiology Ecology 75: 482-496.

Lin, H.C., Hsu, C.H., Chen, H.L., Chung, M.Y., Hsu, J.F., Lien, R.I., Tsao, L.Y., Chen, C.H. and Su, B.H., 2008. Oral probiotics prevent necrotizing enterocolitis in very low birth weight preterm infants: a multicenter, randomized, controlled trial. Pediatrics 122: 693-700.

Lin, H.Y., Chang, J.H., Chung, M.Y. and Lin, H.C., 2013. Prevention of necrotizing enterocolitis in preterm very low birth weight infants: is it feasible? Journal of the Formosan Medical Association, in press. DOI: http://dx.doi.org/10.1016/j.jfma.2013.03.010.

Lodinová-Žádníková, R., Prokešová, L., Kocourková, I., Hrdý, J. and Žižka, J., 2010. Prevention of allergy in infants of allergic mothers by probiotic Escherichia coli. International Archives of Allergy and Immunology 153: 201-206.
Luoto, R., Kalliomäki, M., Laitinen, K. and Isolauri, E., 2010. The impact of perinatal probiotic intervention on the development of overweight and obesity: follow-up study from birth to 10 years. International Journal of Obesity 34: 1531-1537.

Maassen, C.B.M. and Claassen, E., 2008. Strain-dependent effects of probiotic lactobacilli on EAE autoimmunity. Vaccine 26: 2056-2057.

Maldonado, J., Canabate, F., Sempere, L., Velam F., Sanchez, A.R., Narbona, E., Lopez-Huertas, E., Geerlings, A., Valero, A.D., Olivares, M. and Lara-Villoslada, F., 2012. Human milk probiotic Lactobacillus fermentum CECT5716 reduces the incidence of gastrointestinal and upper respiratory tract infections in infants. Journal of Pediatric Gastroenterology and Nutrition 54: 55-61.

Maldonado, J., Lara-Villoslada, F., Sierra, S., Sempere, L., Gomez, M., Rodriguez, J.M., Boza, J., Xaus, J. and Olivares, M., 2010. Safety and tolerance of the human milk probiotic strain Lactobacillus salivarius CECT5713 in 6-month-old children. Nutrition 26: 1082-1087.

Manzoni, P., Lista, G., Gallo, E., Marangione, P., Priolo, C., Fontana, P., Guardione, R. and Farina, D., 2011. Routine Lactobacillus rhamnosus GG administration in VLBW infants: a retrospective, 6-year cohort study. Early Human Development 87 Suppl. 1: S35-S38.

Manzoni, P., Rinaldi, M., Cattani, S., Pugni, L., Romeo, M.G., Messner, H., Stolfi, I., Decembrino, L., Laforgia, N., Vagnarelli, F., Memo, L., Bordignon, L., Saia, O.S., Maule, M., Gallo, E., Mostert, M., Magnani, C., Quercia, M., Bollani, L., Pedicino, R., Renzullo, L., Betta, P., Mosca, F., Ferrari, F., Magaldi, R., Stronati, M. and Farina, D., 2009. Bovine lactoferrin supplementation for prevention of late-onset sepsis in very low-birth-weight neonates: a randomized trial. Journal of the American Medical Association 302: 1421-1428.

Maródi, L., 2006. Innate cellular immune responses in newborns. Clinical Immunology 118: 137-144.

Metchnikoff, E., 1907. Essais Optimistes. A. Maloine, Paris, France. Mihatsch, W.A., Vossbeck, S., Eikmanns, B., Hoegel, J. and Pohlandt, F., 2010. Effect of Bifidobacterium lactis on the incidence of nosocomial infections in very-low-birth-weight infants: a randomized controlled trial. Neonatology 98: 156-163.

Mohan, R., Koebnick, C., Schildt, J., Mueller, M., Radke, M. and Blaut, M., 2008. Effects of Bifidobacterium lactis Bb12 supplementation on body weight, fecal $\mathrm{pH}$, acetate, lactate, calprotectin, and IgA in preterm infants. Pediatric Research 64: 418-422.

Morisset, M., Aubert-Jacquin, C., Soulaines, P., Moneret-Vautrin, D.A. and Dupont, C., 2011. A non-hydrolyzed, fermented milk formula reduces digestive and respiratory events in infants at high risk of allergy. European Journal of Clinical Nutrition 65: 175-183.

Nermes, M., Kantele, J.M., Atosuo, T.J., Salminen, S. and Isolauri, E., 2011. Interaction of orally administered Lactobacillus rhamnosus GG with skin and gut microbiota and humoral immunity in infants with atopic dermatitis. Clinical and Experimental Allergy 41: 370377.

Niers, L., Martin, R., Rijkers, G., Sengers, F., Timmerman, H., Van Uden, N., Smidt, H., Kimpen, J. and Hoekstra, M., 2009. The effects of selected probiotic strains on the development of eczema (the PandA study). Allergy 64: 1349-1358. 
Ou, C.Y., Kuo, H.C., Wang, L., Hsu, T.Y., Chuang, H., Liu, C.A., Chang, J.C., Yu, H.R. and Yang, K.D., 2012. Prenatal and postnatal probiotics reduces maternal but not childhood allergic diseases: a randomized, double-blind, placebo-controlled trial. Clinical and Experimental Allergy 42: 1386-1396.

Panigrahi, P., Parida, S., Pradhan, L., Mohapatra, S.S., Misra, P.R., Johnson, J.A., Chaudhry, R., Taylor, S., Hansen, N.I. and Gewolb, I.H., 2008. Long-term colonization of a Lactobacillus plantarum synbiotic preparation in the neonatal gut. Journal of Pediatric Gastroenterology and Nutrition 47: 45-53.

Petschow, B.W., Figueroa, R., Harris, C.L., Beck, L.B., Ziegler, E. and Goldin, B., 2005. Effects of feeding an infant formula containing Lactobacillus GG on the colonization of the intestine: a dose-response study in healthy infants. Journal of Clinical Gastroenterology 39: 786-790.

Pineiro, M., Asp, N.G., Reid, G., Macfarlane, S., Morelli, L., Brunser, O. and Tuohy, K., 2008. FAO technical meeting on prebiotics. Journal of Clinical Gastroenterology 42: S156-S159.

Ping, Y. and LanJuan L, 2012. The germfree murine animal: an important animal model for research on the relationship between gut microbiota and the host. Veterinary Microbiology 157: 1-7.

Rautava, S., Salminen, S. and Isolauri, E., 2009. Specific probiotics in reducing the risk of acute infections in infancy - a randomised, double-blind, placebo-controlled study. British Journal of Nutrition 101: 1722-1726.

Ritchie, B.K., Brewster, D.R., Tran, C.D., Davidson, G.P., McNeil, Y. and Butler, R.N., 2010. Efficacy of Lactobacillus GG in aboriginal children with acute diarrhoeal disease: a randomised clinical trial. Journal of Pediatric Gastroenterology and Nutrition 50: 619-624.

Rojas, M.A., Lozano, J.M., Rojas, M.X., Rodriguez, V.A., Rondon, M.A., Bastidas, J.A., Perez, L.A., Rojas, C., Ovalle, O., Garcia-Harker, J.E., Tamayo, M.E., Ruiz, G.C., Ballesteros, A., Archila, M.M. and Arevalo, M., 2012. Prophylactic probiotics to prevent death and nosocomial infection in preterm infants. Pediatrics 130: 1113-1120.

Romeo, M.G., Romeo, D.M., Trovato, L., Oliveri, S., Palermo, F., Cota, F. and Betta, P., 2011. Role of probiotics in the prevention of the enteric colonization by Candida in preterm newborns: incidence of late-onset sepsis and neurological outcome. Journal of Perinatology 31: 63-69.

Rose, M.A., Stieglitz, F., Koksal, A., Schubert, R., Schulze, J. and Zielen, S., 2010. Efficacy of probiotic Lactobacillus GG on allergic sensitization and asthma in infants at risk. Allergy 40: 1398-1405.

Rosenfeldt, V., Benfeldt, E., Nielsen, S.D., Michaelsen, K.F., Jeppesen, D.L., Valerius, N.H. and Paerregaard, A., 2003. Effect of probiotic Lactobacillus strains in children with atopic dermatitis. Journal of Allergy and Clinical Immunology 111: 389-395.

Rougé, C., Piloquet, H., Butel, M.J., Berger, B., Rochat, F., Ferraris, L., Des Robert, C., Legrand, A., De la Cochetiére, M.F., N'Guyen, J.M., Vodovar, M., Voyer, M., Darmaun, D. and Roze, J.C., 2009. Oral supplementation with probiotics in very-low-birth-weight preterm infants: a randomized, double-blind, placebo-controlled trial. American Journal of Clinical Nutrition 89: 1828-1835.

Rozé, J.C., Barbarot, S., Butel, M.J., Kapel, N., Waligora-Dupriet, A.J., De Montgolfier, I., Leblanc, M., Godon, N., Soulaines, P., Darmaun, D., Rivero, M. and Dupont, C., 2012. An $\alpha$-lactalbumin-enriched and symbiotic-supplemented v. a standard infant formula: a multicentre, double-blind, randomised trial. British Journal of Nutrition 107: 1616-1622.

Saavedra, J.M., Bauman, N.A., Oung, I., Perman, J.A. and Yolken, R.H., 1994. Feeding of Bifidobacterium bifidum and Streptococcus thermophilus to infants in hospital for prevention of diarrhoea and shedding of rotavirus. The Lancet 344: 1046-1049.

Salmi, H., Kuitunen, M., Viljanen, M. and Lapatto, R., 2010. Cow's milk allergy is associated with changes in urinary organic acid concentrations. Pediatric Allergy and Immunology 21: e401-e406.

Salminen, M.K., Rautelin, H., Tynkkynen, S., Poussa, T., Saxelin, M., Valtonen, V. and Järvinen, A., 2004. Lactobacillus bacteremia, clinical significance, and patient outcome, with special focus on probiotic L. rhamnosus GG. Clinical Infectious Diseases 38: 62-69.

Salminen, M.K., Tynkkynen, S., Rautelin, H., Saxelin, M., Vaara, M., Ruutu, P., Sarna, S., Valtonen, V. and Järvinen, A., 2002. Lactobacillus bacteremia during a rapid increase in probiotic use of Lactobacillus rhamnosus GG in Finland. Clinical Infectious Diseases 35: 11551160.

Samanta, M., Sarkar, M., Ghosh, P., Ghosh, J., Sinha, M. and Chatterjee, S., 2008. Prophylactic probiotics for prevention of necrotizing enterocolitis in very low birth weight newborns. Journal of Tropical Pediatrics 55: 128-131.

Sanders, M.E., 2008. Probiotics: definition, sources, selection, and uses. Clinical Infectious Diseases 46: S58-S61.

Sanders, M.E., Akkermans, L.M., Haller, D., Hammerman, C., Heimbach, J.T., Hörmannsperger, G. and Huys, G., 2010. Safety assessment of probiotics for human use. Gut Microbes 1: 164-185.

Sanders, M.E., Guarner, F., Guerrant, R., Holt, P.R., Quigley, E.M.M., Sartor, R.B., Sherman, P.M. and Mayer, E.A., 2013. An update on the use and investigation of probiotics in health and disease. Gut 62: 787-796.

Sari, F.N., Eras, Z., Dizdar, E.A., Erdeve, O., Oguz, S.S., Uras, N. and Dilmen, U., 2012. Do oral probiotics affect growth and neurodevelopmental outcomes in very low-birth-weight preterm infants? American Journal of Perinatology 29: 579-586.

Savino, F., Cordisco, L., Tarasco, V., Palumeri, E., Calabrese, R., Oggero, R., Roos, S. and Matteuzzi, D., 2010. Lactobacillus reuteri DSM 17938 in infantile colic: a randomized, double-blind, placebocontrolled trial. Pediatrics 126: e526-e533.

Scalabrin, D.M., Johnston, W.H., Hoffman, D.R., P'Pool, V.L., Harris, C.L. and Mitesser, S.H., 2009. Growth and tolerance of healthy term infants receiving hydrolyzed infant formulas supplemented with Lactobacillus rhamnosus GG: randomized, double-blind, controlled trial. Clinical Pediatrics 48: 734-774.

Soh, S.E., Aw, M., Gerez, I., Chong, Y.S., Rauff, M., Ng, Y.P.M., Wong, H.B., Pai, N., Lee, B.W. and Shek, L.P.C., 2009. Probiotic supplementation in the first 6 months of life in at risk Asian infants - effects on eczema and atopic sensitization at the age of 1 year. Clinical and Experimental Allergy 39: 571-578.

Soh, S.E., Ong, D.Q.R., Gerez, I., Zhang, X., Chollate, P., Shek, L.P.C., Lee, B.W. and Aw, M., 2010. Effect of probiotic supplementation in the first 6 months of life on specific antibody responses to infant hepatitis B vaccination. Vaccine 28: 2577-2579. 
Szajewska, H., Gyrczuk, E. and Horvath, A., 2013. Lactobacillus reuteri DSM 17938 for the management of infantile colic in breastfed infants: a randomized, double-blind, placebo-controlled trial. Journal of Pediatrics 162: 257-262.

Taipale, T., Pienihäkkinen, K., Isolauri, E., Larsen, C., Brockmann, E., Alanen, P., Jokela, J. and Söderling, E., 2011. Bifidobacterium animalis subsp. lactis BB-12 in reducing the risk of infections in infancy. British Journal of Nutrition 105: 409-416.

Taipale, T., Pienihäkkinen, K., Salminen, S., Jokela, J. and Söderling, E., 2012. Bifidobacterium animalis subsp. lactis BB-12 administration in early childhood: a randomized clinical trial of effects on oral colonization by mutans streptococci and the probiotic. Caries Research 46: 69-77.

Teran, C.G., Teran-Escalera, C.N. and Villarroel, P., 2009. Nitazoxanide vs. probiotics for the treatment of acute rotavirus diarrhoea in children: a randomized, single-blind, controlled trial in Bolivian children. International Journal of Infectious Diseases 13: 518-523.

Underwood, M.A., Salzman, N.H., Bennett, S.H., Barman, M., Mills, D., Marcobal, A., Tancredi, D.J., Bevins, C.L. and Sherman, M.P., 2009. A randomized placebo-controlled comparison of two prebiotic/ probiotic combinations in preterm infants: impact on weight gain, intestinal microbiota, and fecal short chain fatty acids. Journal of Pediatric Gastroenterology and Nutrition 48: 216-225.

Van Baarlen, P., Troost, F., Van der Meer, C., Hooiveld, G., Boekschoten, M., Brummer, R.J. and Kleerebezem, M., 2011. Human mucosal in vivo transcriptome responses to three lactobacilli indicate how probiotics may modulate human cellular pathways. Proceedings of the National Academy of Sciences of the USA 108 Suppl. 1: 4562-4569.

Van der Aa, L.B., Heymans, H.S., Van Aalderen, W.M., Sillevis Smitt, J.H., Knol, J., Ben Amor, K., Goossens, D.A., Sprikkelman, A.B. and the Synbad Study Group., 2010. Effect of a new synbiotic mixture on atopic dermatitis in infants: a randomized-controlled trial. Clinical and Experimental Allergy 40: 795-804.

Van der Aa, L.B., Lutter, R., Heymans, H.S.A., Smids, B.S., Dekker, T., Van Aalderen, W.M.C., Sillevis Smitt, J.H., Knippels, L.M.J., Garssen, J., Nauta, A.J., Sprikkelman, A.B. and the Synbad Study Group., 2012. No detectable beneficial systemic immunomodulatory effects of a specific synbiotic mixture in infants with atopic dermatitis. Clinical and Experimental Allergy 42: 531-539.

Van der Aa, L.B., Van Aalderen, W.M.C., Heymans, H.S.A., Sillevis Smitt, J.H., Nauta, A.J., Knippels, L.M.J., Ben Amor, K., Sprikkelman, A.B. and the Synbad Study Group., 2011. Synbiotics prevent asthmalike symptoms in infants with atopic dermatitis. Allergy 66: 170-177.
Velaphi, S.C., Cooper, P.A., Bolton, K.D., Mokhachane, M., Mphahlele, R.M., Beckh-Arnold, E., Monaheng, L. and Haschke-Becher, E., 2008. Growth and metabolism of infants born to women infected with human immunodeficiency virus and fed acidified whey-adapted starter formulas. Nutrition 24: 203-211.

Vlieger, A.M., Robroch, A., Van Buuren, S., Kiers, J., Rijkers, G., Benninga, M.A. and Te Biesebeke, R., 2009. Tolerance and safety of Lactobacillus paracasei ssp. paracasei in combination with Bifidobacterium animalis ssp. lactis in a prebiotic-containing infant formula: a randomised controlled trial. British Journal of Nutrition 102: 869-875.

Von Wright, A., 2005. Regulating the safety of probiotics - the European approach. Current Pharmaceutical Design 11: 17-23.

Vyas, U. and Ranganathan, N., 2012. Probiotics, prebiotics, and synbiotics: gut and beyond. Gastroenterology Research and Practice 2012: 872716.

West, C.E., Gothefors, L., Granström, M., Käyhty, H., Hammarström, M.L. and Hernell, O., 2008. Effects of feeding probiotics during weaning on infections and antibody responses to diphtheria, tetanus and Hib vaccines. Pediatric Allergy and Immunology 19: 53-60.

West, C.E., Hammarström, M.L. and Hernell, O., 2009. Probiotics during weaning reduce the incidence of eczema. Pediatric Allergy and Immunology 20: 430-437.

Weston, S., Halbert, A., Richmond, P. and Prescott, S.L., 2005. Effects of probiotics on atopic dermatitis: a randomised controlled trial. Archives of Disease in Childhood 90: 892-897.

Wickens, K., Black P.N., Stanley, T.V., Mitchell, E., Fitzharris, P., Tannock, G.W., Purdie, G., Crane, J. and the Probiotic Study Group, 2008. A differential effect of 2 probiotics in the prevention of eczema and atopy: a double-blind, randomized, placebo controlled trial. Journal of Allergy and Clinical Immunology 122: 788-794.

Wickens, K., Black, P., Stanley, T.V., Mitchell, E., Barthow, C., Fitzharris, P., Purdie, G. and Crane, J., 2012. A protective effect of Lactobacillus rhamnosus HN001 against eczema in the first 2 years of life persists to age 4 years. Clinical and Experimental Allergy 42: 1071-1079.

Yamasaki, C., Totsu, S., Uchiyama, A., Nakanishi, H., Masumoto, K., Washio, Y., Shuri, K., Ishida, S., Imai, K. and Kusuda, S., 2012. Effect of Bifidobacterium administration on very-low-birth weight infants. Pediatrics International 54: 651-656.

Youngster, I., Kozer, E., Lazarovitch, Z., Broide, E. and Goldman, M., 2011. Probiotics and the immunological response to infant vaccinations: a prospective, placebo controlled pilot study. Archives of Disease in Childhood 96: 345-349. 